\title{
New World Order
}

I t seems that wherever you turn these days you read another headline about the increasing popularity of outsourcing software development. On a whim, I stopped by Google's news page where a search of "outsourcing software development" produced eight stories on the first page written in the last 24 hours (with the remaining two not significantly older than that). No surprise, the headlines include such frenzied folly as "outsourcing craze," "job fears," and the latest entrant- "backlash." That last one is enough to trip my sensors that global software development outsourcing is a cemented new feature of the landscape. Once there's a backlash to something, you know it has fully arrived.

This is the new world order: software development on a global scale. As is almost always the case, this doesn't mean the entire technical arm of a corporation breaking off and floating across an ocean in one clean clump, but rather numerous small teams here and there "sharing the pain" across time zones. Nowadays it's not atypical to have multiple teams on multiple continents working on the same project. It's not just financial pressures that come to bear and break developers into teams. The sheer size-raw lines of code-of many of today's projects means they're just too big for one group to handle on its own. And whether teams are spread across a campus or across multiple continents, distributed development affects the way that we write code.

How does this affect software development? How do we deal with it? Well, true to our mission, ACM Queue isn't going to answer any of those questions. Instead, we've put together a collection of articles on the topic that will help you reach answers of your own while facing the technical, and sometimes not-so-technical, challenges of developing software in a distributed environment.

First up we have Mike Turnlund, a director of engineering for a little company you might know, Cisco. Mike has taken stock of all past lessons learned as a way to explore what's hard about multi-team, multi-site development. Tool selection, architecture decisions, Mike's covered it.

Then we've got an insightful piece, "The Sun Never Sets on Distributed Development," by Ken Coar, director of the Apache Foundation-and you know managing the

\section{Outsourcing \\ development MEANS}

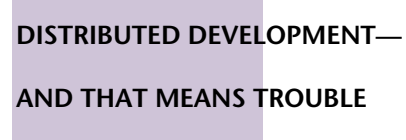

FOR THE UNPREPARED.
Apache project means managing a distributed development process.

Of course this begs the question, if distributed

development is so hard, why aren't there better tools for it? Why can't we attach this instant message to that line of code as a comment? Well, Li-Te Cheng and crew from IBM ask the hard questions, and report on their findings in "Building Collaboration into IDEs."

Judy and Gary Olson from the University of Michigan round out our special report and dig at what is far too often the root of the problems you'll face in distributed development: culture clashes. Read their "Culture Surprises in Remote Software Development Teams" and get a new perspective.

No issue of Queue would be complete without one of our interviews, and this month we've done a distributed interview. For this, the West Coast's Tony Wasserman, principal at Software Methods and Tools, rings up East Coast rep Steve Hagan, head of Oracle's New England Development Center in Nashua, New Hampshire, to see how Oracle handles the new world order.

Despite the all-encompassing nature of distributed development and the way it does (or soon will) affect us all, we managed to scare up a couple of great articles on other topics for this issue. If you've ever wanted to debug binary, don't miss James Whittaker and Herbert Thompson's "Black Box Debugging." And then there's Gordon Bell-yes, the Gordon Bell-with a self-diagnostic for vaporware-producing businesses. Does your company qualify?

I might add that Eric Allman is particularly curmudgeonly in this month's Curmudgeon column, "The Economics of Spam." Enjoy! Q

EDWARD GROSSMAN is responsible for Queue, so blame him if you don't like it. In earlier incarnations he was a development project manager at a still-in-business dot-com and a closet coder (his parents still don't know-_Our son Ed? Oy, he works with computers, doing something"). 